\title{
When is the Ideal Time to Perform Brain MRI in Patients with Transient Global Amnesia? Analysis of Case Series with Transient Global Amnesia from Previous Studies, based on Imaging Findings of Diffusion MRI According to Time Criteria
}

\section{Georgios-Theofilos Theodorou ${ }^{1,2}$, Elisavet Psoma ${ }^{3 *}$, Xanthipi Mavropoulou $^{3}$, Aikaterini Terzoudi ${ }^{1,4}$ and Konstantinos Vadikolias ${ }^{1,4}$}

${ }^{1}$ Postgraduate Program "Stroke" of the Medical School of the Democritus University of Thrace, Alexandroupolis, Greece

${ }^{2}$ Laboratory of Clinical Neurophysiology, Aristotle University of Thessaloniki, AHEPA University Hospital, Thessaloniki, Greece

${ }^{3}$ Department of Clinical Radiology, Aristotle University of Thessaloniki, AHEPA

University Hospital, Thessaloniki, Greece

${ }^{4}$ Department of Neurology, University Hospital of Alexandroupolis, Democritus

University of Thrace, School of Medicine, Alexandroupolis, Greece

*Corresponding Author: Elisavet Psoma, Department of Clinical Radiology, Aristotle University of Thessaloniki, AHEPA University Hospital, Thessaloniki, Greece.
Received: November 08,2021

Published: December 20, 2021

(C) All rights are reserved by Elisavet Psoma., et al.

\section{Abstract}

Objective: To determine the role of diffusion-weighted imaging (DWI) magnetic resonance studies in diagnosis of Transient Global Amnesia in patients who fulfilled the clinical diagnostic criteria.

Methods: In this systemic review study, 214 patients from 17 previous studies, who fulfilled the clinical diagnostic criteria of transient global amnesia were analyzed, based on imaging findings of DWI MRI according to temporal criteria. PubMed was meticulously searched.

Results: DWI findings in at least one hippocampus were found in 180 of 214 patients, regardless of the time the MRI performed. This accounted for the majority, 84.1\%, of all patients who met the diagnostic criteria for TGA. Hippocampal DWI lesions were more common on the left one. The percentages of positive neuroimaging findings compared to the time the episode of TGA begins and the clinical signs are apparent as follows: $84,1 \%$ in general, $26 \%$, when the examination is performed within the first day, $71,9 \%$ in approximately 24 hours, $87,2 \%$ at 36 hours, $82,3 \%$ at 48 hours, $72,7 \%$ at 72 hours, $42,8 \%$, when performed in the first days but after 72 hours and $0 \%$, when performed on a remote date, indicating the transient nature of the episode.

Conclusion: According to the results of the present study, the best time to perform cranial MRI DWI seems to be between 36 to 48 hours after the initiation of the clinical semiology of transient global amnesia.

Keywords: DWI; MRI; Transient Global Amnesia; Hippocampus

\section{Abbreviations}

DWI: Diffusion Weighted Imaging; TGA: Transient Global Amnesia

\section{Introduction}

Transient global amnesia (TGA) is a benign memory disorder of unknown origin. The clinical picture lasts up to 24 hours [2-4] and

Citation: Elisavet Psoma., et al. "When is the Ideal Time to Perform Brain MRI in Patients with Transient Global Amnesia? Analysis of Case Series with Transient Global Amnesia from Previous Studies, based on Imaging Findings of Diffusion MRI According to Time Criteria". Acta Scientific Neurology 5.1 (2022): 06-10. 
When is the Ideal Time to Perform Brain MRI in Patients with Transient Global Amnesia? Analysis of Case Series with Transient Global Amnesia from Previous Studies, based on Imaging Findings of Diffusion MRI According to Time Criteria

is characterized by transient prospective and retrospective amnesia with neither disturbance of the level of consciousness nor focal neurologic signs [5-8]. High signal isolated punctate hippocampal lesions, at DWI, in CA1 area of the hippocampus, as a manifestation of dysfunction of this area, is a very common finding [6,9,10-11].

At the onset of the condition, in almost $80-90 \%$ of patients, there is transient disturbance in the DWI of the hippocampus [12]. These neuroimaging findings are absent after two weeks, as are findings from the T2 and FLAIR sequences [6].

With the present study, we start from the fact that high signal at MRI DWI in the medial temporal lobes is a very common finding in patients with TGA [13-15] and we try to identify what is the best time to perform DWI. We reviewed case reports and case series of patients with TGA, independently of their years of age, to stratify the imaging findings of DWI MRI according to time criteria.

\section{Materials and Methods}

PubMed was used to identify studies, case reports and case series, which described the findings of MRI diffusion sequence in pa- tients who met the diagnostic criteria of transient global amnesia. We used the following terms to investigate our subject: TGA, MRI, DWI, time criteria. Patients of any age with TGA were selected. Only studies in the English language published from 1998 to the first months of 2020 were selected. In case of studies that were conducted in the same country with common authors, we selected only the one with the highest number of cases, to ensure objectivity, by avoiding recurrence of the same cases, and greater representativeness through the largest number of patients. An absolute selection criterion of the studies was the clear documentation of the time of the MRI DWI examination compared to the time of presentation. With this methodology, 17 studies were selected from total 58 studies. Subsequently, the patients who met the diagnostic criteria for transient global amnesia, were accounted and stratified about the presence of high signal in hippocampus at the DWI, according to the time between the onset of memory impairment and when MRI was performed. Diffusion disorders were observed exclusively in one or both hippocampi and reported. Otherwise, patients with findings in other cerebral locations, as in the thalamus or cerebellum, were excluded. The results of the analyses are shown in detail in the table below (Table 1).

\begin{tabular}{|c|c|c|c|c|c|c|c|c|c|}
\hline No & Study/year & $\mathbf{n}$ & $\mathrm{Nt}<24 \mathrm{~h}$ & $\mathrm{Nt}=24 \mathrm{~h}$ & $\mathrm{Nt}=36 \mathrm{~h}$ & $\mathrm{Nt}=48 \mathrm{~h}$ & $\mathrm{Nt}=72 \mathrm{~h}$ & $\mathrm{Nt}>72 \mathrm{~h}$ & Nt $\sim$ \\
\hline 1 & Demas 2019 [2] & $2 / 2$ & & & & $\begin{array}{l}1 / 1 \\
1 \mathrm{~B}\end{array}$ & $\begin{array}{c}1 / 1 \\
1 \mathrm{~B}\end{array}$ & & \\
\hline 2 & $\begin{array}{c}\text { K.Jan and S. Chuin } \\
2018[10]\end{array}$ & $1 / 1$ & & & $\begin{array}{c}1 / 1 \\
1 \mathrm{R}\end{array}$ & & & & \\
\hline 3 & Inokuchi 2016 [11] & $1 / 1$ & $0 / 1$ & $\begin{array}{c}1 / 1 \\
1 \mathrm{~B}\end{array}$ & & & & & \\
\hline 4 & Abreu Junior 2018 [3] & $5 / 5$ & $0 / 1$ & $\begin{array}{c}2 / 2 \\
1 \mathrm{~L}, 1 \mathrm{~B}\end{array}$ & $\begin{array}{c}3 / 3 \\
1 \mathrm{~L}, 1 \mathrm{R}, 1 \mathrm{~B}\end{array}$ & & & & \\
\hline 5 & Bartsch 2006 [7] & $30 / 41$ & $\begin{array}{c}8 / 14 \\
4 \mathrm{~L}, 1 \mathrm{R}, 3 \mathrm{~B}\end{array}$ & $\begin{array}{c}5 / 7 \\
3 \mathrm{~L}, 1 \mathrm{R} \\
1 \mathrm{~B} \\
\end{array}$ & & $\begin{array}{c}8 / 12 \\
4 \mathrm{R}, 4 \mathrm{~L}\end{array}$ & $\begin{array}{c}\text { 6/9 4R, } \\
1 \mathrm{~B}, 1 \mathrm{~L}\end{array}$ & $\begin{array}{l}1 / 1 \\
1 \mathrm{R}\end{array}$ & \\
\hline 6 & Jian Li 2012 [8] & $\begin{array}{c}1 / 1 \\
1 \mathrm{~B}\end{array}$ & $\begin{array}{c}1 / 1 \\
1 \mathrm{~B}\end{array}$ & $0 / 1$ & & & & & \\
\hline 7 & $\begin{array}{c}\text { Jungeun Kim } 2012 \\
\text { [13] }\end{array}$ & $96 / 111$ & & $\begin{array}{c}78 / 111 \\
32 \mathrm{~L} \\
30 \mathrm{R} \\
16 \mathrm{~B} \\
\end{array}$ & $\begin{array}{c}96 / 111 \\
37 \mathrm{~L}, 28 \mathrm{R} \\
31 \mathrm{~B}\end{array}$ & & & & \\
\hline 8 & Sedlaczek 2004 [14] & $\begin{array}{c}26 / 31 \\
15 \mathrm{~L}, 6 \mathrm{R}, 5 \mathrm{~B}\end{array}$ & $2 / 31$ & $23 / 31$ & & $26 / 31$ & & $0 / 2$ & \\
\hline 9 & Strupp 1998 [4] & $\begin{array}{l}7 / 10 \\
3 \mathrm{~B}, 4 \mathrm{~L}\end{array}$ & $2 / 2$ & $4 / 4$ & $2 / 2$ & & & $0 / 2$ & \\
\hline 10 & CianFoni 2005 [12] & $4 / 4$ & & & & $2 / 2$ & $1 / 1$ & $1 / 1$ & $0 / 1$ \\
\hline
\end{tabular}

Citation: Elisavet Psoma., et al. "When is the Ideal Time to Perform Brain MRI in Patients with Transient Global Amnesia? Analysis of Case Series with Transient Global Amnesia from Previous Studies, based on Imaging Findings of Diffusion MRI According to Time Criteria". Acta Scientific Neurology 5.1 (2022): 06-10. 
When is the Ideal Time to Perform Brain MRI in Patients with Transient Global Amnesia? Analysis of Case Series with Transient Global Amnesia from Previous Studies, based on Imaging Findings of Diffusion MRI According to Time Criteria

\begin{tabular}{|c|c|c|c|c|c|c|c|c|c|}
\hline 11 & $\begin{array}{c}\text { Kuan-Yu Lin } 2020 \\
{[16]}\end{array}$ & $\begin{array}{c}1 / 1 \\
1 \mathrm{R}\end{array}$ & & & & $\begin{array}{c}1 / 1 \\
1 \mathrm{R}\end{array}$ & & & \\
\hline 12 & Matsui 2002 [17] & $\begin{array}{l}1 / 1 \\
1 \mathrm{R}\end{array}$ & & & & $\begin{array}{c}1 / 1 \\
1 \mathrm{R}\end{array}$ & & & $0 / 1(14 d)$ \\
\hline 13 & Wilkinson 2013 [18] & $\begin{array}{l}1 / 1 \\
1 \mathrm{~B}\end{array}$ & & & & $\begin{array}{l}1 / 1 \\
1 \mathrm{~B}\end{array}$ & & & $0 / 1(23 d)$ \\
\hline 14 & $\begin{array}{c}\text { Alastair John Stewart } \\
2015 \text { [19] }\end{array}$ & $\begin{array}{l}1 / 1 \\
1 \mathrm{~B}\end{array}$ & & & & $\begin{array}{c}1 / 1 \\
1 \mathrm{~B}\end{array}$ & & & \\
\hline 15 & Della Marca 2010 [15] & $\begin{array}{c}1 / 1 \\
1 \mathrm{~L}\end{array}$ & & & $\begin{array}{c}1 / 1 \\
1 \mathrm{~L}\end{array}$ & & & & $0 / 1(60 d)$ \\
\hline 16 & $\begin{array}{c}\text { Atsuhib } \\
\text { Sugiyama } 2015[20]\end{array}$ & $\begin{array}{l}1 / 1 \\
1 \mathrm{R}\end{array}$ & & & & & & $\begin{array}{c}1 / 1 \\
1 \mathrm{R}(5 \mathrm{~d})\end{array}$ & $\begin{array}{c}0 / 1 \\
(>100 d)\end{array}$ \\
\hline 17 & $\begin{array}{l}\text { Jone Bocos-Portillo } \\
2018[21]\end{array}$ & $\begin{array}{c}1 / 1 \\
1 \mathrm{~B}\end{array}$ & & & & $\begin{array}{c}1 / 1 \\
1 \mathrm{~B}\end{array}$ & & & \\
\hline & Total & $180 / 214$ & $13 / 50$ & $113 / 157$ & $103 / 118$ & $42 / 51$ & $8 / 11$ & $3 / 7$ & \\
\hline & Percentage $\%$ & $84,1 \%$ & $26 \%$ & $71,9 \%$ & $87,2 \%$ & $82,3 \%$ & $72,7 \%$ & $42,8 \%$ & $0 \%$ \\
\hline
\end{tabular}

Table 1

Table 1 the serial number of the study, Study/Year: we mention the first name of the author of each study and the publication date, in order to certify that there are no repetitive results, having the same source of patients. $n$ : the number of positive results divided by the total number of MRI exams in each study. $\mathrm{Nt}<24 \mathrm{~h}$ : the number of patients who had findings in DWI when the examination was performed in up to 24 hours of the beginning of the clinical presentation, divided by the number of patients who had an MRI at this time period. $\mathrm{Nt}=24 \mathrm{~h}$ : the number of patients who had findings in DWI when the examination was performed at 24 hours of the beginning of the clinical presentation, divided by the number of patients who had an MRI at this time period. Nt = 36h: the number of patients who had findings in DWI when the examination was performed at 36 hours of the beginning of the clinical presentation, divided by the number of patients who had an MRI at this time period. $\mathrm{Nt}=48 \mathrm{~h}$ : the number of patients who had findings in DWI when the examination was performed at 48 hours of the beginning of the clinical presentation, divided by the number of patients who had an MRI at this time period. $\mathrm{Nt}=72 \mathrm{~h}$ : the number of patients who had findings in DWI when the examination was performed at 72 hours after the beginning of the clinical presentation, divided by the number of patients who had an MRI at this time period. Nt $>72 \mathrm{~h}$ : the number of patients who had findings in DWI when the examination was performed at the first days after the beginning of the clinical presentation, and after 72 hours, divided by the number of patients who had an MRI at this time period. Nt $\sim$ : the number of patients who had findings in DWI, when the examination was performed in a long time, after the day of the episode, divided by the number of patients who had MRI exam in that time. B: bilateral finding in the hippocampus. L: finding only in the left hippocampus. R: finding only in the right hippocampus.

\section{Results}

We found that in 180 of 214 patients there were imaging findings in DWI, in at least one hippocampus, regardless of the time the MRI performed. This accounted for the majority, $84.1 \%$, of all patients who met the diagnostic criteria for TGA. Some patients underwent more than one MRI examinations. The total number of MRI examinations with findings in the DWI sequence were 248. Of these 103 showed localizations with high signal in the left hippocampus, 79 in the right hippocampus and 68 had bilateral findings. The findings included mostly spotted areas of high signal either in one area or multiple, including multiple areas of the same hippocampus. In all patients who underwent follow-up neuroimaging, in a time frame of over 2 weeks, the initial findings had resolved.

The percentages of positive neuroimaging findings compared to the time the episode of TGA begins and the clinical signs are apparent as follows: $84,1 \%$ in general, $26 \%$, when the examination is performed within the first day, 71,9\%, when performed in approximately 24 hours, $87,2 \%$, when performed at 36 hours, $82,3 \%$, when performed at 48 hours, $72,7 \%$, when performed at 72 hours,

Citation: Elisavet Psoma., et al. "When is the Ideal Time to Perform Brain MRI in Patients with Transient Global Amnesia? Analysis of Case Series with Transient Global Amnesia from Previous Studies, based on Imaging Findings of Diffusion MRI According to Time Criteria". Acta Scientific Neurology 5.1 (2022): 06-10. 
$42,8 \%$, when performed in the first days but after 72 hours and $0 \%$, when performed on a remote date, indicating the transient nature of the episode.

\section{Discussion}

Transient global amnesia (TGA) is a disease of unknown cause. The clinical picture lasts up to 24 hours and is characterized by transient prospective and retrospective amnesia with neither disturbance of the level of consciousness nor focal neurologic semiology $[5,6,16,17]$. High signal focal lesions, at MRI DWI, in CA1 area of the hippocampus, as a manifestation of dysfunction of this area, is a very common finding $[6,9]$.

Caplan first formulated the diagnostic criteria of TGA, which Hodges and Warlow, and subsequently Quinette., et al. Later analyzed and certified [1].

Despite the various proposed theories about etiology, TGA remains a disease of unknown cause. At the onset of the condition, in almost $80-90 \%$ of patients, there is transient disturbance in the MRI DWI of the hippocampus, as we can see in this study. These neuroimaging findings are absent after two weeks, as are findings from the T2 and FLAIR sequences [6].

According to the present study an imaging finding of diffusion disturbance in the hippocampus is quite specific to the diagnosis of TGA and particularly sensitive, especially when the examination is performed within the first three days from the start of the episode. The sensitivity of the MRI-DWI examination in diagnosing TGA is variable and depends largely on the time it was performed following the beginning of the episode. The percentages of positive neuroimaging findings have the following distribution: $84,1 \%$ in general, $26 \%$ when the examination is performed within the first day, $71,9 \%$ in approximately 24 hours, $87,2 \%$, when performed at 36 hours, $82,3 \%$ at 48 hours, $72,7 \%$ at 72 hours, $42,8 \%$ when performed in the first days but after 72 hours and we have no neuroimaging findings when performed on a remote date, indicating the transient nature of the episode.

Combining the above percentages with the standard knowledge that the clinical semiology of transient global amnesia resolves at most in 24 hours, we can interestingly conclude that the imaging findings in the DWI sequence appear, mainly, after the clinical semiology and obvious symptomatology of transient global amnesia have resolved. That is, the imaging findings are absent when clinical semiology is present, while on the contrary we have positive imaging findings when the semiology has almost completely receded.

In this study we recognize that there are some limitations. First, we do not have accurate information for all patients studied, for instance the presence of vascular risk factors or for about the duration of the episode, somewhat that differentiate the pure TGA from the transient epileptic amnesia [1]. Additionally, and most importantly in only 6 studies of the 17 the patients underwent follow-up brain MRI. Based on that someone would raise the objection that the different percentages of positive neuroimaging findings compared to the time the episode of TGA begins could be random and that the clinical episodes were transient ischemic attacks rather than TGA. All the objections are rational and reveal some limitations about this study. However, in the last question we can answer that hippocampal infarctions from posterior cerebral artery ischemia, have different size and different topography, compared to the localization of the diffusion restriction on MRI in patients with transient global amnesia affecting the CA1 region and the punctuated distribution that are highly characteristic in TGA [22].

\section{Conclusion}

According to the results of the present study, the best time to perform MRI DWI seems to be between 36 to 48 hours after the initiation of the clinical features of transient global amnesia preferably observed by a clinician. We believe that a more detailed prospective study with accurate information about personal and family medical history precipitating incidents, vascular risk factors, episode duration and a plan of neuroimaging follow-up for all patients on a remote date after the clinical incident, could be more precise.

\section{Study Funding}

No targeted funding reported.

\section{Conflict of Interest}

Nothing to declare.

\section{Bibliography}

1. Hodges JS and Warlow CP. "Syndromes of transient amnesia: towards a classification. A study of 153 cases". Journal of Neurology, Neurosurgery, and Psychiatry 53 (1990): 834-843. 
2. Demas A., et al. "Transient global amnesia with bilateral hippocampal lesions: report of two cases". Acta Neurologica Belgica 120.6 (2020): 1449-1451.

3. De Abreu Junior L., et al. "Optimization of magnetic resonance imaging protocol for the diagnosis of transient global amnesia”. Radiologia brasileira 52.3 (2019): 161-165.

4. Strupp M., et al. "Diffusion-Weighted MRI in Transient Global Amnesia; Elevated Signal Intensity in the Left Mesial Temporal Lobe in 7 of 10 Patients". Annals of Neurology 43.2 (1998): 164-170.

5. Agosti C., et al. "Transient global amnesia and brain lesions: new hints into clinical criteria". European Journal of Neurology 15 (2008): 981-984.

6. Spiegel DR., et al. "Transient global amnesia: current perspectives-review". Neuropsychiatric Disease and Treatment 13 (2017): 2691-2703.

7. Bartsch T., et al. "Selective affection of hippocampal CA-1 neurons in patients with transient global amnesia without longterm sequelae". Brain 129 (2006): 2874-2884.

8. Li J and Hu WL. "Case Report Bilateral hippocampal abnormalities in magnetic resonance imaging in transient global amnesia". American Journal of Emergency Medicine 755.31 (2013): $1-3$.

9. Bartsch T and Deuschl G. "Transient global amnesia: functional anatomy and clinical implications". Lancet Neurology 9.2 (2010): 205-214.

10. Jan K and Chuin S. "A case of recurrent transient global amnesia: don't forget the hippocampal punctuate diffusion restriction". Oxford Medical Case Reports 6 (2018): 182-185.

11. Inokuchi R., et al. "A healthy woman with sudden memory loss". The Journal of Emergency Medicine 1 (2016): 1-2.

12. Cianfoni A., et al. "Hippocampal Magnetic Resonance Imaging Abnormalities in Transient Global Amnesia". Archives of Neurology 62 (2005): 1468.

13. Kim J., et al. "Clinical Experience of Modified Diffusion-Weighted Imaging Protocol for Lesion Detection in Transient Global Amnesia: An 8-Year Large-Scale Clinical Study". Journal of Neuroimaging 24.4 (2014): 331-337.
14. Sedlaczek O., et al. "Detection of delayed focal MR changes in the lateral hippocampus in transient global amnesia". Neurology 62.2 (2004): 2165-2170.

15. Della Marca G., et al. "The Stolen Memory: A Case of Transient Global Amnesia". Biological Psychiatry 67 (2010): 31-32.

16. Lin KY., et al. "Positive Magnetic Resonance Imaging Evidence of Transient Global Amnesia Following the Use of Sildenafil”. Clinical Neuropharmacology 43.2 (2020) :52-53.

17. Matsui M., et al. "Transient global amnesia: increased signal intensity in the right hippocampus on diffusion-weighted magnetic resonance imaging". Neuroradiology 44 (2002): 235-238.

18. Wilkinson T., et al. "Neuroimaging in transient global amnesia". Practical Neurology 13 (2013): 56-57.

19. Webb AJS and Rothwell PM. "Transient global amnesia associated with bilateral restricted diffusion in the lateral hippocampus". Journal of Neurology, Neurosurgery, and Psychiatry 84 (2013): 522.

20. Sugiyama A., et al. "Transient global amnesia with a hippocampal lesion followed by transient epileptic amnesia". Seizure 31 (2015): 141-143.

21. Bocos-Portillo J., et al. "Unilateral or bilateral punctate hippocampal hyperintensities on DW-MRI: seizures, amnesia, or both?" Neurological Sciences 39.9 (2018): 1647-1649.

22. Bartsch T and Deuschl G. "Transient global amnesia: functional anatomy and clinical implications". Lancet Neurology 9.2 (2010): 205-214.

\section{Assets from publication with us}

- Prompt Acknowledgement after receiving the article

- Thorough Double blinded peer review

- Rapid Publication

- Issue of Publication Certificate

- High visibility of your Published work

Website: www.actascientific.com/

Submit Article: www.actascientific.com/submission.php

Email us: editor@actascientific.com

Contact us: +919182824667

Citation: Elisavet Psoma., et al. "When is the Ideal Time to Perform Brain MRI in Patients with Transient Global Amnesia? Analysis of Case Series with Transient Global Amnesia from Previous Studies, based on Imaging Findings of Diffusion MRI According to Time Criteria". Acta Scientific Neurology 5.1 (2022): 06-10. 